\title{
More sustainable tomorrow's transport systems based on Big Data concerning travel preferences
}

\author{
Grzegorz Sierpiński ${ }^{1}$ \\ ${ }^{1}$ Silesian University of Technology, Faculty of Transport and Aviation Engineering, Department of Transport Systems and \\ Traffic Engineering \\ Krasińskiego Str. 8, 40-019 Katowice, Poland
}

\section{Extended Abstract}

Congestion is one of negative phenomenon typical of contemporary cities. In many of them, the percentage share of travel by car is much higher than for other types of travel. A change in the modal distribution of traffic is needed in favor of environmentally friendly transport. Changes in behaviour of people travelling are not easy and fast. They require a proper approach and smart measures. For this reason, it is important to develop a relevant strategy to introduce those changes in coming years. An efficient urban transport system should respond to the needs of the travelling population. On the other hand, it is exactly for the appropriate development of the system that one can adapt behaviour patterns of the travelling population to the requirements imposed by sustainable development. Consequently, the behaviour patterns displayed by travellers are challenges for local authorities.

Transport preferences have a significant impact on the functioning of the transport system and the city or region in general. Under the international research project "Electric travelling - platform to support the implementation of electromobility in Smart Cities based on ICT applications" within the scope of ERA-NET CoFund Electric Mobility Europe Programme financed among others from the means of the National Centre for Research and Development. specified Big Data server has been constructed and developed. It is a part of ICT solution called ET Sys. The database can be used in the system for forecasting future requirements of for example charging stations and as a support in decisionmaking on changes of transport systems. Data is collected during the travel planning process by the traveler (user of ET Sys). Registered parameters include the date of planned travel, start time and place (geographical coordinates), end place, preferred mean of transport (user may choose one of 12 modes), motivation (among others home, work, education, shopping, service, duty travel, medic, administration, sport, entertainment etc.), preferred optimization criteria, and other parameters of the travel.

Collected data allows to analyse the actual transport system and helps with making a decision on the changes to be introduced - like modification of bus lines, new locations of charging stations for electric vehicles, implementation of electric urban car rental systems etc. The approach can be used in the future through standardization data and their aggregation to meet global ITS standards. As a result of these actions, a more sustainable transport system with green mobility can be obtained.

\section{Acknowledgements}

The present research has been financed from the means of the National Centre for Research and Development as a part of the international project within the scope of ERA-NET CoFund Electric Mobility Europe Programme "Electric travelling platform to support the implementation of electromobility in Smart Cities based on ICT applications". 